\title{
A Case of Pulmonary Mucormycosis Presenting with Endobronchial Involvement
}

\author{
Hakan Tanrıverdi ${ }^{1}$, Figen Atalay $^{2}$, Levent Kart ${ }^{3}$, Murat Altuntaş ${ }^{4}$, Ayşegül Tomruk ${ }^{2}$
}

${ }^{1}$ Clinic of Chest Diseases, Erzincan State Hospital, Erzincan

${ }^{2}$ Department of Chest Diseases, Karaelmas University Faculty of Medicine, Zonguldak

${ }^{3}$ Clinic of Chest Diseases, Bezmialem Vakif University Faculty of Medicine, İstanbul

${ }^{4}$ Uzun Mehmet Chest and Occupational Disesases Hospital, Zonguldak

\begin{abstract}
Mucormycosis is an opportunistic fungal infection that is rare but has a fatal course, occurs especially in patients with immunodeficiency, and is caused by fungi in the Zygomycetes class. Since the infection is generally caused by inhalation of spores, mostly the paranasal sinuses and lungs are affected. Diabetes mellitus and hematologic malignancies are the most common underlying diseases. It usually initiates like bacterial pneumonia, and its clinical and radiologic findings are nonspecific. Thus, a high index of suspicion is necessary. Combined medical and surgical treatment methods are recommended. We aimed to present a case of pulmonary mucormycosis with a course of endobronchial involvement.
\end{abstract}

Keywords: Endobronchial involvement, opportunistic infections, pneumonia, pulmonary mucormycosis

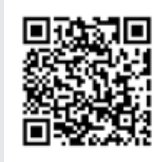

Received Date: 28.11 .2011

Accepted Date: 18.02.2012

Available Online Date: 27.10.2014

Address for correspondence

Hakan Tanriverdi, Clinic of Chest Diseases,

Erzincan State Hospital, Erzincan, Turkey

E-mail: hakante2000@yahoo.com

(C) Copyright 2014 Turkish Respiratory Society (TRS) Eurasian J Pulmonol 2014

DOI: 10.5152/ejp.2014.02439

-Available online at www.eurasianjpulmonol.com

\section{INTRODUCTION}

Mucormycosis is an opportunistic infection that is severe and usually has a fatal course, caused by fungi from the Mucorales order of the Zygomycetes class (1). Sometimes, zygomycosis is used as a general term; however, since other fungi from the Zygomycetes class also cause non-opportunistic infections, some authors use the term mucormycosis (2). Mucormycosis occurs especially in patients with immunodeficiency. The most common clinical conditions associated with mucormycosis are diabetes mellitus, hematologic malignancies, and renal failure. The increasing number of patients transplanted and receiving high-dose cancer chemotherapy also causes the number of patients with mucormycosis to increase (4). It has five dominant clinical forms. These are the rhinocerebral, pulmonary, disseminated, cutaneous, and gastrointestinal forms, according to their incidence. Pulmonary mucormycosis occurs like bacterial pneumonia as a result of the inhalation of pathogenic spores at the beginning, but they may cause severe infections, becoming rapidly fatal in patients with suppressed immune systems, like poorly controlled diabetes patients with ketoacidosis (4). Pulmonary infections are the most common causes of morbidity and mortality in patients with suppressed immune systems and the most common opportunist is pulmonary mycosis (5). The disease is relatively rare, and most of the reported patients are in the form of small series or isolated case presentations (6). Thus, in this study, we aimed to present a case of pulmonary mucormycosis presenting with endobronchial involvement in accordance with the literature, in order to draw attention to this rarely seen but usually fatal opportunist fungal infection.

\section{CASE PRESENTATION}

A 58-year-old male patient applied to the Zonguldak Karaelmas University Medical Faculty Hospital Emergency Service with dyspnea, cough, sputum, and general poor health complaints. He had a history of type 2 diabetes mellitus and had been using insulin for 5 years. As a result of the physical examination, the findings were as follows: fever: $36.8^{\circ} \mathrm{C}$, pulse: $112 / \mathrm{min}$, blood pressure: $110 / 70 \mathrm{~mm} \mathrm{Hg}$, oxygen saturation $\left(\mathrm{Sat}_{2}\right.$ ): $80 \%$, and respiration rate: $22 / \mathrm{min}$. Bilateral diffuse rhonchi and bibasilar rales at the end of inspiration were heard. Laboratory test results of the patient were found as: white blood cell count: $22.8 \times 10^{9} / \mathrm{L}, \mathrm{Hgb}: 13.5 \mathrm{~g} / \mathrm{dL}$, blood sugar: $530 \mathrm{mg} / \mathrm{dL}$, $\mathrm{pH}$ of blood gas drawn on room 
air: 7.30, $\mathrm{pCO}_{2}: 30 \mathrm{mmHg}, \mathrm{pO}_{2}: 44 \mathrm{mmHg}, \mathrm{HCO}_{3}: 18 \mathrm{mEq} / \mathrm{L}$, and Sat $\mathrm{O}_{2}$ : $77 \%$. In his chest radiography, there were blunting in the right costophrenic sinus, volume loss in the right hemithorax, bulk-like homogeneous density increase, and heterogeneous infiltration from hilus lying to the periphery in the left middle zone (Figure 1). The patient was hospitalized with diagnoses of acute exacerbation of chronic obstructive pulmonary disease (COPD), pneumonia, diabetic ketoacidosis, malignancy, and respiratory insufficiency. Since the patient had bilateral infiltration, general poor health, acidosis in his blood gas and comorbid diseases, he was taken to the intensive care unit for close follow-up and monitoring with diagnoses of severe pneumonia and respiratory insufficiency; however, invasive mechanical ventilation was not applied. In spite of non-specific antibiotherapy [ceftriaxone 2x1 gr intravenous (IV) and clarithromycin 2x1 $500 \mathrm{mg}$ oral], bronchodilator, and support therapy, there was no regression in his chest radiography or symptoms. His thorax computed tomography (CT) revealed bilateral pleural effusion, constriction in the right main bronchus upper lobe bifurcation, and consolidation areas, where air bronchograms were observed in the posterobasal and medial segment of right lower lobe of the lung (Figure 2). It was observed in the bronchoscopic examination that the right bronchial system was covered with muco-necrotic exudates surrounding the whole mucosa from the main bronchus and leading to constriction in the lumen. A biopsy and bronchial lavage were taken from the lesion. The Zygomycetes group of fungi reproduced in the bronchial lavage culture. Fungal hyphae were observed in the histopathological examination of the mucosal biopsy. Therefore, IV classical amphotericin B treatment was initiated for the patient. The patient, having partial clinical improvement with amphotericin B treatment, was discharged from the intensive care unit. On the 6th day of the treatment, the patient was lost as a result of massive hemoptysis.

\section{DISCUSSION}

Mucormycosis is the third most common opportunist mycosis seen in patients with hematologic malignancy. It generally occurs in patients with severe neutropenia (7). The other main predisposing conditions are uncontrolled diabetes mellitus, acidosis, renal failure, deferoxamine treatment, severe burns, and immunosuppression following solid organ transplantation $(8,9)$. It was first reported by Paltauf in 1885 (10). It has five dominant clinical forms, in particular: pulmonary, rhinocerebral, dermatological, gastrointestinal, and pervasive. Most commonly, rhinocerebral and pulmonary involvement is seen. The most important underlying disease in patients with mucormycosis is diabetes, since it reproduces in an acidic and glucose-rich medium (11). In the three large reviews published over the last 20 years, the most important underlying diseases in patients having received pulmonary mucormycosis were reported as diabetes mellitus (32\%-56\%) and hematologic malignancy $(32 \%-37 \%)(6,12,13)$. It was reported that the majority of the patients with diabetes had type 2 diabetes (80\%) and that there was a clinical picture of documented ketoacidosis in $48 \%$ of the patients with type 1 diabetes and $34 \%$ of the patients with type 2 diabetes (13). Our case was also a type 2 diabetes patient and was using insulin for 5 years. He had $530 \mathrm{mg} / \mathrm{dL}$ blood sugar when he came, and there was metabolic acidosis in his blood gas. His having ketoacidosis and a 12.2 value of $\mathrm{HbA1C}$ indicated that he had poorly controlled diabetes. Two pulmonary mucormycosis cases published by Bilgin et al. (14), having regulated diabetes with just diet and fungal diseases occurring in this phase, contradict the information in the literature. Pulmonary mucormycosis is seen in sensitive individuals inhaling pathogen spores. Inhalation of spores

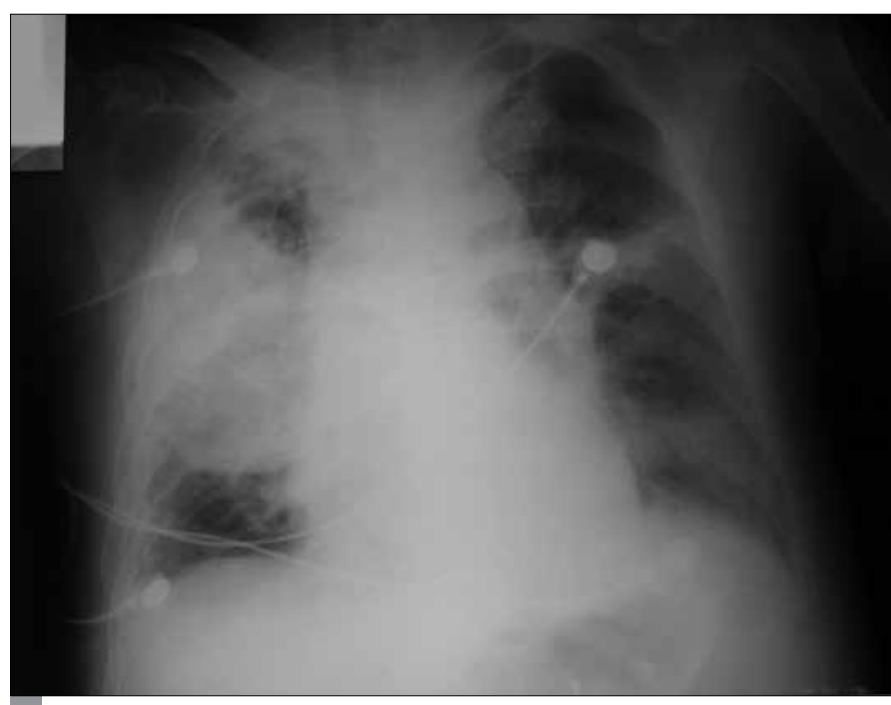

Figure 1. In PA chest radiography, a mass-like consolidation area in the right middle zone and subsegmental atelectasis in the left

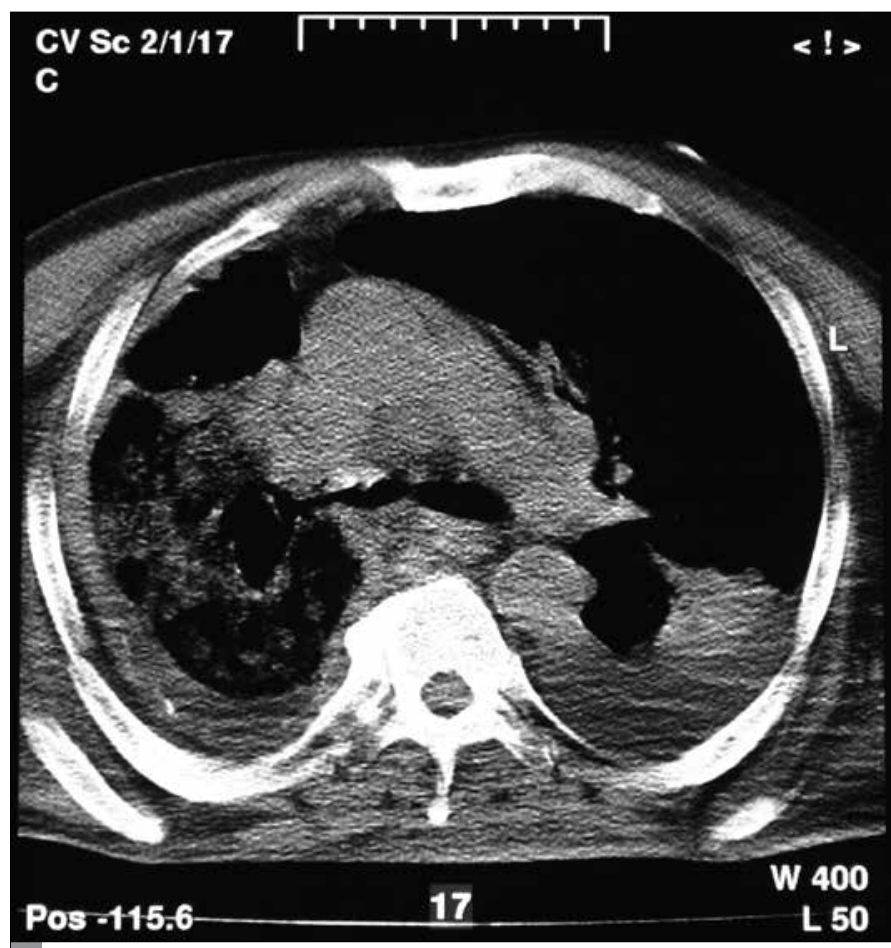

Figure 2. Thorax CT: Bilateral pleural effusion, consolidation area in the right middle and lower lobes and constriction in the right main bronchus

may cause colonization; however, it does not occur in healthy people, as inhaled spores are eliminated by pulmonary macrophages. If these mechanisms are disrupted, invasive infection appears. Steroids inhibit spore germination control of macrophages, and chemotaxis of polymorphonuclear leukocytes is disrupted in patients with diabetes (6). Pulmonary mucormycosis has two forms. The most common form is the parenchymal disease, which occurs with consolidation in the lung and leads to respiratory failure rapidly. Another form is the endobronchial disease, affecting the large airways (15). In our case, there was both parenchymal and endobronchial involvement. The clinical and radiological findings in mucormycosis are non-specific, 
and they are similar to bacterial pneumonia. While the most common radiological findings are infiltration and mass, pulmonary consolidation, cavitation, and effusion are seen less frequently. The most common symptoms are reported as fever, cough, and pleuritic chest pain (6). Since a microbiological examination is conducted in less than $50 \%$ of the cases, early diagnosis of mucormycosis is highly difficult. The differential diagnosis of pulmonary mucormycosis involves bacterial, viral, and other fungal pneumonias. Candida and Aspergillus are the most frequent opportunistic pulmonary fungi. The most common causes of delayed diagnosis are the simultaneous existence of viral or bacterial infections, not suspecting the disease, and difficulty of reproduction of fungi with conventional techniques (6). While the most frequent pre-mortem diagnosis is made by bronchoscopy, the most common technique is transbronchial biopsy (12). Since there was also endobronchial involvement in our case, a mucosa biopsy was conducted. A final diagnosis was established as a result of seeing fungal hyphae in the biopsy and reproduction of Rhizopus type fungus in the bronchial lavage culture. Endobronchial mucormycosis is fairly rare in the literature. They are generally defined as lesions, formed of grey-white mucoid material, obstructing large airways. Airway involvement is typically edematous and necrotic (16). In the bronchoscopic examination of our patient, it was observed that the right bronchial system was filled with muco-necrotic material covering the whole mucosa, beginning from the carina and leading to luminal obstruction. Donahue et al. (15) reported that there was susceptibility to endobronchial involvement in patients with diabetes. In a review conducted, it was reported that $85 \%$ of patients with endobronchial involvement had diabetes, as in our case (12). Hemoptysis is seen more in mucormycosis than bacterial pneumonias. Destruction takes place in the bronchial structure of these patients as a result of tissue necrosis and vascular invasion causing mucosal ulceration. Hyphae penetrate the bronchial wall and invade the blood vessels and, especially, the arterioles. Thrombosis and embolization with vascular invasion, ischemia, hemorrhagic infarction, and tissue necrosis appear. Hyphae give rise to severe and fatal bleeding by separating the internal elastic membrane of large pulmonary vessels and the media layer (6). Our case was also lost due to massive hemoptysis. Aggressive management is recommended for pulmonary mucormycosis. Fungi cause local invasive infections having a high mortality rate, as a result of massive hemoptysis-associated asphyxia. Although the medical treatment with intravenous amphotericin B is successful in some cases, the combination of surgical resection and medical treatment is recommended. The aim of the surgery is the removal of infected tissue. Wide resections, including pneumonectomy, were reported in patients having proximal and wide spreads. Mortality was significantly lower only in cases undergoing surgical treatment versus cases undergoing medical treatment.

\section{CONCLUSION}

Consequently, mucormycosis is a rare but life-threatening disease. The gradually increasing number of immunosuppressed patients also leads to the increase of this disease. Suspicion of opportunistic pulmonary infection has to be high in every immunosuppressed patient. An aggressive diagnostic approach is necessary for patients having persistent fever and pulmonary findings progressing, despite antibiotics. The nonspecific clinical and radiological findings of these patients, low diagnostic efficiency of sputum in opportunist infections in the early periods, and the simultaneous presence of other infections may create difficulty in the diagnosis. Performing additional diagnostic operations, such as bronchoscopy in the early periods, prevents diagnostic delay.

Informed Consent: Written informed consent was obtained from patients' parents who participated in this study.

Peer-review: Externally peer-reviewed.

Author contributions: Concept - H.T., F.A.; Design - H.T., L.K., F.A.; Supervision F.A., M.A., A.T.; Resource - H.T, A.T., M.A.; Materials - H.T., F.A., A.T.; Data Collection and/or Processing - H.T., F.A.; Analysis and/or Interpretation - H.T., F.A.; Literature Review - M.A., A.T., L.K.; Writing - H.T., F.A.; Critical Review - L.K., F.A., M.A.

Conflict of Interest: No conflict of interest was declared by the authors.

Financial Disclosure: The authors declared that this study has received no financial support.

\section{REFERENCES}

1. Parfrey NA. Improved diagnosis and prognosis of mucormycosis: A clinicopathologic study of 33 cases. Medicine 1986; 65: 113-23. [CrossRef]

2. McAdams HP, Rosado de Christenson M, Strollo DC, Patz, EF Jr. Pulmonary Mucormycosis: Radiologic Findings in 32 Cases. AJR Am J Roentgenol 1997; 168: 1541-8. [CrossRef]

3. Ingram CW, Sennesh J, Cooper JN, Perfect JR. Disseminated zygomycosis: report of four cases and review. Rev Infect Dis 1989; 11: 741-54. [CrossRef]

4. Meyer RD, Rosen P, Armstrong D. Phycomycosis complicating leukemia and lymphoma. Ann Intern Med 1972; 77: 871-9. [CrossRef]

5. Fanta $\mathrm{CH}$, Pennington JE. Fever and new lung infiltrates in the immunocompromised host. Clin Chest Med 1981; 2: 19-39.

6. Tedder M, Spratt JA, Anstadt MP, Hegde SS, Tedder SD, Lowe JE. Pulmonary mucormycosis: results of medical and surgical therapy. Ann Thorac Surg 1994; 57: 1044-50. [CrossRef]

7. Chandler FW. Watts JC. Fungal infections. In: Dall DH, Hammer SP, eds. Pulmonary pathology. New York: Springer-Verlag. 1988: 228-31. [CrossRef]

8. Rinaldi MG. Zygomycosis. Infect Dis Clin North Am 1989; 3: 19-41.

9. Lehrer RI, Howard DH, Sypherd PS. Edwards JE. Segal OP. Winston DJ. Mucormycosis. Ann Intern Med 1980; 93: 93-108. [CrossRef]

10. Sugar AM. Agents of mucormycosis and related species. In: Mandell GL Bennett JE, Dolin R, eds. Principles and practice of infectious diseases, 4th ed. NewYork: Chumhill Livingstone, 1995; 2311-21.

11. Carbone KM, Pennington LR, Gimenez LF, Burrow CR, Watson AJ. Mucormycosis in renal transplant patients: a report of two cases and review of the literature. Q J Med 1985; 57: 825-31.

12. Lee FY, Mossad SB, Adal KA. Pulmonary mucormycosis: the last 30 years. Arch Intern Med 1999; 159: 1301-9. [CrossRef]

13. Roden MM, Zaoutis TE, Buchanan WL, Knudsen TA, Sarkisova TA, Schaufele $\mathrm{RL}$, et al. Epidemiology and outcome of zygomycosis: a review of 929 reported cases. Clin Infect Dis 2005; 41: 634-53. [CrossRef]

14. Bilgin $\mathrm{M}$, Oğuzkaya F, Oymak S, Canöz Ö, Pulmonary mucormycosis: Case presentation of two cases. Erciyes Med J 2003; 25: 200-3.

15. Donohue JF, Scott RJ, Walker DH, Bromberg PA. Phycomycetes: a cause of bronchial obstruction. South Med J 1980; 73: 734-6. [CrossRef]

16. Husari AW, Jensen WA, Kirsch CM, Campagna AC, Kagawa FT, Hamed KA, et al. Pulmonary mucormycosis presenting as an endobronchial lesion. Chest 1994; 106: 1889-91. [CrossRef]

17. Bigby TD, Serota ML, Tierney LM Jr, Matthay MA. Clinical spectrum of pulmonary mucormycosis. Chest 1986; 89: 435-9. [CrossRef] 